\title{
Emotional Intelligence Among Women: A Systematic Review
}

\author{
Seri Suhaila Binti Abdullah, Azlina Kosnin, Yeo Kee Jiar
}

\begin{abstract}
Background: Emotional intelligence (EI) involves a combination of competencies which allow a person to be aware of, to understand the emotions of others and to use this knowledge to foster their and others success. Objective: This study aims to provide a systematic review of published researches on the emotional intelligence among women. Methodology: To achieve this aims, papers were selected in January 2019 with search terms "Emotional intelligence" "Emotional intelligence among women" and "Gender in emotional intelligence" from five databases: Scopus, PsycINFO, Springer, Google Scholar, and ScienceDirect. 26 research based article were evaluated published from 2010 to 2018. Results: The analysis the published articles considered two basic central themes in the study of emotional intelligence among women: level of women emotional intelligence and emotional intelligence attributes. The study revealed the level of emotional intelligence is low, meaning that women are less emotionally intelligent. Similarly, the study identified ten (10) emotional intelligence attributes among women which include empathy, social responsibility, stress tolerance, emotional self-awareness, emotional expression, independence, flexibility, problem solving, impulse control, interpersonal relationships and optimism. Conclusions: Considering the results of various studies analysed in this review clearly, identified methodological weakness in emotional intelligence study such as sample size most of the studies but only few studies recognised and report the limitation. Similarly, none of these studies investigate the causes of this low state of emotional intelligence among women. The findings add to the growing empirical evidence regarding emotional intelligence. Future researches should look into some of these limitation and address sample size challenges, for batter generalization of research findings, sample size should always be considered. Future work should as well examine in more detail the role of cognitive or other factors in determining the emotional intelligence among women
\end{abstract}

Index Terms: Keywords: Emotional Intelligence, Gender, Systematic Review, Women.

\section{INTRODUCTION}

Emotional intelligence as a concept is currently in focus among the general public, practitioners and researchers. It's being widely believed by the public that emotional and social competence is as important, or even more important, than traditional dimension of personality and intellectual ability (Goleman, 1995, 1998).

Emotional Intelligence is "the ability to perceive emotions, integrate emotions to facilitate thought understand emotions, and to regulate emotions to promote personal growth, (Mayer et al. 1999). Emotional Intelligence consists

Revised Manuscript Received on April 19, 2019.

Seri Suhaila Binti Abdullah, School of Education, Faculty of Social Science and Humanities, University Teknologi Malaysia, (Email: pnrajaputra336@gmail.com)

Azlina Kosnin, School of Education, Faculty of Social Science and Humanities, University Teknologi Malaysia.

Yeo Kee Jiar, School of Education, Faculty of Social Science and Humanities, University Teknologi Malaysia. of two domains, ability and personality. The domain of ability emotional intelligence includes cognitive abilities regarding emotions (Mayer et al 2000a, 2000b). The domain of trait or personality emotional intelligence focuses on control of impulses, optimism, and assertiveness (Petrides and Furnham 2001). The word emotion is Latin word which is "emover" means to move, to excite or agitate This word is used in modern times for expression of love, hate, attraction, anger or any other kind of feeling. Emotions are important for business as well as personal relationships. Affective, personal and social factors are included to non-intellective as well as intellective elements. Non-Intellective elements are helpful for person to predict other ability of person for success in life. Emotional intelligence is lifelong learned process through experiences as person become mature his emotional competencies would be lead to happy life and would be better perform at workplace. Through emotional intelligence an employee become well in their work, move, creative and its results in overall better productive at workplace.

Emotional intelligence is defined as "the composite set of capabilities that enable a person to manage himself/herself and others" (Goleman, 1995, 1998). "It is more accurate to say that the frequency with which a person demonstrates or uses the constituent capabilities, or competencies, inherent in emotional intelligence determine the ways in which he/she deals with themselves, their life, work and others" (Boyatzis, Goleman and Rhee, 2000). It is the ability to: 1) be aware to understand and to express oneself; 2) be aware of, to understand, and to relate to others, 3 ) deal with strong emotions and control one's impulses; and 4) adapt to change and to solve problems of a personal or a social nature (BarOn, 1988)

Emotional intelligence is important key construct in today's Psychology; it has linked with aid of lavish interpersonal media attention. It is scientific understanding that emotional intelligence is key construct helpful for person to train their emotional skills as well as for living as more fulfilling and productive. Emotional intelligence has own importance due to management of emotions of person in modern society (Zeidner, Matthews and Roberts 2004). It is fact that emotional intelligence can be improved and by trained in various places like schools, (educational systems, occupational and personal place where emotional intelligence program can launch for increase emotional intelligence in peoples. Principles of emotional intelligence

Published By: 
provide a new way of person to understand and assessment of emotions, behavioral management style, attitudes of person and interpersonal skills that are very important for development of any organizations or workplace. Emotional intelligence has very much important in any organization for recruitment of jobs, selection of employees, management of organization, relationship of customer and services. Emotional intelligence is based on performance theory that is merit based (Goleman 1998). There are two models of emotional intelligence which are mental ability model and mixed model (Zeidner, Matthews and Roberts, 2004).

Previous researches show the comparison of men and women in a way that ability emotional intelligence women obtain high score as compare to men (Barchard 2001; Meyer and Geher 1996; Mayer, Salovey, Caruso 2000a; Mayer, Salovey and Caruso 2000b). A research also shows that women are more emotionally intelligence than men (Beisecker and Barchard 2004). Past researches indicated that girls have higher interpersonal skills than boys (Mayer, Caruso and Salovey 1999; Palmer et al. 2003). A study conducted on adolescents regarding gender and age difference in emotional intelligence, its results shows that gender not age was correlated with emotional intelligence. Gender and age have an importance on emotional intelligence, as males have high score in intrapersonal intelligence as compare to female, while female has high score on interpersonal intelligence. Female were more active in building relationship with their utilizations of emotions as well as regulating emotions. Female are more emotionally aware and have high level of interpersonal skills of intelligence (Palmer et al. 2003).

Individuals who have skills for coping in activities of life, they are also productive thinkers with ability of affective awareness (Abraham 1999). Usually people with more emotional intelligence possesses more life satisfaction, more ordered, optimistic, warm, and prosperous and partake in others emotions (Salaski and Gartwright 2002). It is beneficial in many ways for any organization that their selection of employees would be on the basis of high level of emotional intelligence. Emotional intelligence is based on performance theory which includes all abilities related to cognitive and affective skills (Goleman 1998). Employee who are emotionally intelligent they have performed better in organization that is why emotional intelligence is important for any organization (Law, Wong and Song 2004).

\section{OBJECTIVE}

This study aims to provide a systematic review of published researches on the emotional intelligence among women.

\section{METHODOLOGY}

To achieve this aims, papers were selected in January 2019 with search terms "Emotional intelligence", "Emotional intelligence among women" and "Gender in emotional intelligence" from five databases: Scopus, PsycINFO, Springer, Google Scholar, and ScienceDirect. 15 research based article were evaluated published from 2011 to 2018. Other materials of relevant studies were searched using Google Scholar. During the initial phase, there was no limitation on searching relevant studies, all research papers, concept papers, conference and other technical or government reports. Hence, the search found a total of 167 papers which stated about emotional intelligence. In the second phase the number of articles were reduced to 26 articles and in the third phase 15 articles that, satisfied the inclusion criteria i.e (1) The selected articles were limited to those published from 2010 to 2018 (2) The emotional intelligence studies conducted with a sample of female (3) Empirical, emotional intelligence studies with involving both gender in a comparison.

\section{FINDINGS AND DISCUSSIONS}

The results of this review depict the main themes that are relevant for Emotional intelligence study related to gender in terms of basic central themes: the level of women emotional intelligence and emotional intelligence attributes.

These main themes are: in terms of the level of women emotional intelligence and emotional intelligence attributes, out of the 15 studies reviewed 9 studies show that, women have low level of emotional intelligence, 5 studies show that, there are eleven (11) emotional intelligence attributes which include empathy, social responsibility, stress tolerance, emotional self-awareness, emotional expression, independence, flexibility, problem solving, impulse control, interpersonal relationships and optimism. The 15 articles are clustered per two main themes in table I and table II.

The findings for each of these two main themes are described below. In the description of all themes, the researcher clearly focuses on the question what the literature in each theme contributes in understanding of Emotional intelligence among women. Due to the selection criteria in this review the descriptions of the themes are based on 13 and 5 articles as interpreted respectively.

Table I: Analysis on level of Women Emotional Intelligence

\begin{tabular}{|c|c|c|c|c|}
\hline Studies & Women & $\begin{array}{l}\text { Both } \\
\text { Genders }\end{array}$ & $\begin{array}{l}\text { Low } \\
\text { Level }\end{array}$ & $\begin{array}{l}\text { Higher } \\
\text { Level }\end{array}$ \\
\hline Rao \& Komala, 2017 & & $\sqrt{ }$ & $\sqrt{ }$ & \\
\hline Joyce \& Magesh, 2017 & $\sqrt{ }$ & & $\sqrt{ }$ & \\
\hline $\begin{array}{l}\text { Mathivanan \& Chileshe, } \\
2013\end{array}$ & & $\sqrt{ }$ & & $\sqrt{ }$ \\
\hline Bhatti, 2013 & & $\sqrt{ }$ & $\sqrt{ }$ & \\
\hline Shin, 2011 & & $\sqrt{ }$ & $\sqrt{ }$ & \\
\hline $\begin{array}{l}\text { Ajmal, Javed \& Javed, } \\
2017\end{array}$ & & $\sqrt{ }$ & $\sqrt{ }$ & \\
\hline Ashkan Khalili, (n.d) & & $\sqrt{ }$ & $\sqrt{ }$ & \\
\hline Saini, 2014 & & $\sqrt{ }$ & & $\sqrt{ }$ \\
\hline Sahua \& Dasb, 2016 & & $\sqrt{ }$ & & $\sqrt{ }$ \\
\hline $\begin{array}{l}\text { Fernández-Berrocal, et } \\
\text { al., } 2012\end{array}$ & & $\sqrt{ }$ & & $\sqrt{ }$ \\
\hline Meshkat and Nejati, 2017 & & $\sqrt{ }$ & $\sqrt{ }$ & \\
\hline $\begin{array}{l}\text { Ahmad Khan \& Ahmad } \\
\text { Bhat, } 2013\end{array}$ & & $\sqrt{ }$ & $\sqrt{ }$ & \\
\hline $\begin{array}{l}\text { Shehzad \& Mahmood, } \\
2013\end{array}$ & & $\sqrt{ }$ & $\sqrt{ }$ & \\
\hline
\end{tabular}




\section{A. Level of Emotional Intelligence among Women}

Thirteen (13) empirical studies Emotional Intelligence (EI) among women were selected: All the 15 studies shows that, emotional intelligence exist in women at different levels, however, 9 out of the 13 selected for this themes shows that, the level of emotional intelligence among women is very low as in many studies compared to men. Joyce and Magesh, (2017) shows that, the level of emotional intelligence among women employees working in IT sector is low. Similarly, Bhatti (2013) using a sample of women who are employees of government and non-governmental organizations revealed that, women at both government and non-governmental organizations have low levels of emotional intelligence.

Table II: Analysis on Emotional Intelligence Attributes.

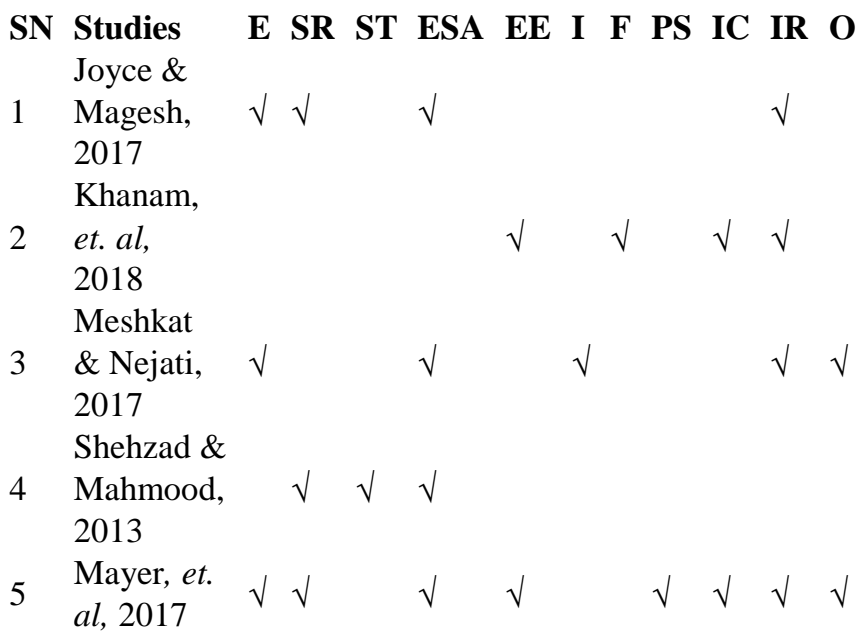

\section{*E=Empathy, $\mathbf{S R}=$ Social Responsibility, $\mathbf{S T}=\mathbf{S t r e s s}$ \\ Tolerance, ESA=Emotional Self-Awareness,EE- \\ Emotional Expression, I=Independence, F=Flexibility, PS=Problem Solving, IC=Impulse Control, IR=Interpersonal Relationships, $\mathrm{O}=$ Optimism}

\section{B. Emotional Intelligence Attributes among Women}

Result of the review in respect of the emotional intelligence attributes among women. The sub-themes are described below as presented in table II above. The five (5) selected studies (Joyce and Magesh, 2017; Khanam, et. al, 2018; Meshkat and Nejati, 2017; Shehzad and Mahmood, 2013 and Mayer, et. al, 2017) revealed that, the major components or attributes of emotional intelligence necessary among women include: empathy, social responsibility, stress tolerance, emotional self-awareness, emotional expression, independence, flexibility, problem solving, impulse control, interpersonal relationships and optimism

\section{CONCLUSION}

This study reviewed some empirical studies on the level of women emotional intelligence and emotional intelligence attributes. The findings add to the growing empirical evidence regarding emotional intelligence. Future researches should look into some of these limitation and address sample size challenges, for batter generalization of research findings, sample size should always be considered. Future work should as well examine in more detail the role of cognitive or other factors in determining the emotional intelligence among women.

Considering the results of various studies analysed in this review clearly, identified methodological weakness in emotional intelligence study such as sample size most of the studies but only few studies recognised and report the limitation. Out of all these reviewed studies only one was conducted with women sample only, the rest were conducted with a combination of both gender. Similarly, none of these studies investigate the causes of this low state of emotional intelligence among women. This research provides new and original context-specific insights on EI among women; these findings can be used as a basis for future research on EI among women of different status while providing a knowledge base for contemporary EI research

\section{REFERENCES}

1. Abraham, R. (1999). Emotional intelligence in organizations: A conceptualization. Genetic, Social, and General Psychology. Monographs, 125, 209-227

2. Bar-On, R.A. (1988). Negative effects of destructive criticism: impact on conflict, serf-efficacy and task performances. Appl. Psychol. 73:199-207

3. Beisecker, M. \& Barchard, K. A. (2004). Sex Differences in Ability Measures of Emotional Intelligence. Poster presented at the Western Psychological Association Annual Convention, Phoenix, Arizona.

4. Bhatti, A. G. (2013). An analysis of the general and gender difference regarding emotional intelligence among employees: evidence from government and nongovernment organizations of Hyderabad. KASBIT Business Journal, 6:106-113

5. Boyatzis, R. E., D. Goleman, K. \& Rhee. (2000). Clustering competence in emotional intelligence: insights form the Emotional Competence Inventory (ECI). In R. Bar-On and J. D. A. Parker (Eds), Handbook of Emotional Intelligence. San Francisco. Jossey Bars

6. Fernández-Berrocal, P., Cabello, R., Castillo, R., Extremera, N. (2012). Gender differences in emotional intelligence: The mediating effect of age. Behavioural Psychology, 20, 77-89.

7. Goleman, D. (1995). Emotional intelligence. New York: Bantam books.

8. Goleman, D. (1998). Working with emotional intelligence. New York: Bantam Books.

9. Khanam, N., Sahu, T, Rao, E. V., Gaidhane, A. (2018). A study on various dimensions of emotional intelligence among doctors. International Journal Community Med Public Health, 5:390-4.

10. Mathivanan, D. \& Chileshe, C (2013). Comparison of male and female differences in emotional intelligence among trained Universities Athletes of Lusaka Province, Zambia. European Researcher, 2013, Vol. (55), № 7-2 1938

11. Mayer J, Salovey, P. \& Caruso, D. R. (2000a). Emotional Intelligence As Zeitgeist, A Personality, and As A Standard Intelligence. In Handbook of Emotional Intelligence,ed. R Bar-On, JDA Parker, pp. 92-117. New York: Jossey-Bass

12. Mayer J, Salovey, P. \& Caruso, D.R. (2000b). Models of emotional intelligence. In handbook of intelligence, ed. RJ Sternberg, pp. 396-420. Cambridge, UK: Cambridge Univ. Press 
13. Mayer, C-H., Oosthuizen, R.M., \& Surtee, S. (2017). Emotional intelligence in South African women leaders in higher education. SA Journal of Industrial Psychology/SA Tydskrif vir Bedryfsielkunde, 43(0), a1405. https://doi.org/10.4102/ sajip.v43i0.1405

14. Mayer, J. D., Caruso, D. R. \& Salovey, P. (1999). Emotional intelligence meets traditional standards for intelligence. Intelligence 27(4): 267-298.

15. Meshkat, M., \& Nejati, R. (2017). Does Emotional Intelligence Depend on Gender? A Study on Undergraduate English Majors of Three Iranian Universities. SAGE Open. https://doi.org/10.1177/2158244017725796

16. Palmer, B. R., Gardner, L. \& Stough, C. (2003). The relationship between emotional intelligence, personality and effective leadership, 5th Australian Industrial \& Organizational Psychology Conference, Melbourne.

17. Petrides, K. V. \& Furnham, A. (2001). Trait emotional intelligence: Psychometric investigation with reference to established trait taxonomies. Europ. J. of Personality, 15, 425-448

18. Sahu,T. L \& Das, R. P. (2016). Gender difference and emotional intelligence in selected hospitals - A Study. World Scientific News 59 (2016) 1-11

19. Saini, K (2014). Gender differences in emotional Intelligence among sportspersons of University of Rajasthan. Thesis Submitted to the University of Rajasthan for the degree of Doctor of Philosophy in Physical Education

20. Salaski, M., \& Gartwright, S. (2002). Health, performance and emotional intelligence: An exploratory study of retail managers, 8, 63 68. (Retrieved from http://www.interscience.wiley.com)

21. Shehzad, S. \& Mahmood, N. (2013). Gender differences in emotional intelligence of university teachers. Pakistan Journal of Social and Clinical Psychology, Vol. 11, No.1, 16-21

22. Shin, L. T. (2011). Gender differences in emotional intelligence: are you as smart as you think emotionally? A research project submitted in partial fulfilment of the requirements for the Bachelor of Social Science (Hons) Psychology Universiti Tunku Abdul Rahman

23. Zeidner, M., Matthews, G. \& Roberts, R. (2004) Emotional Intelligence in the Workplace: A Critical Review. Applied Psychology: An International Review, 53 (3), 371-99. 